\title{
Impacts of Aerosol Shortwave Radiation Absorption on the Dynamics of an Idealized Convective Atmospheric Boundary Layer
}

\author{
E. Barbaro • J. Vilà-Guerau de Arellano • M. C. Krol • \\ A. A. M. Holtslag
}

Received: 31 August 2012 / Accepted: 22 January 2013 / Published online: 22 February 2013

(C) The Author(s) 2013. This article is published with open access at Springerlink.com

\begin{abstract}
We investigated the impact of aerosol heat absorption on convective atmospheric boundary-layer (CBL) dynamics. Numerical experiments using a large-eddy simulation model enabled us to study the changes in the structure of a dry and shearless CBL in depthequilibrium for different vertical profiles of aerosol heating rates. Our results indicated that aerosol heat absorption decreased the depth of the CBL due to a combination of factors: (i) surface shadowing, reducing the sensible heat flux at the surface and, (ii) the development of a deeper inversion layer, stabilizing the upper CBL depending on the vertical aerosol distribution. Steady-state analytical solutions for CBL depth and potential temperature jump, derived using zero-order mixed-layer theory, agreed well with the large-eddy simulations. An analysis of the entrainment zone heat budget showed that, although the entrainment flux was controlled by the reduction in surface flux, the entrainment zone became deeper and less stably stratified. Therefore, the vertical profile of the aerosol heating rate promoted changes in both the structure and evolution of the CBL. More specifically, when absorbing aerosols were present only at the top of the CBL, we found that stratification at lower levels was the mechanism responsible for a reduction in the vertical velocity and a steeper decay of the turbulent kinetic energy throughout the CBL. The increase in the depth of the inversion layer also modified the potential temperature variance. When aerosols were present we observed that the potential temperature variance became significant already around $0.7 z_{i}$ (where $z_{i}$ is the CBL height) but less intense at the entrainment zone due to the smoother potential temperature vertical gradient.
\end{abstract}

Keywords Aerosol heat absorption - Boundary-layer vertical structure · Large-eddy simulation · Surface heat flux 


\section{Introduction}

How shortwave (SW) radiation and aerosols interact in the atmosphere is one of the largest uncertainties in climate prediction (Satheesh and Ramanathan 2000; Tripathi 2005; Johnson et al. 2008). Aerosols modify the vertical profile of radiative heating by absorbing and scattering radiation (Quijano et al. 2000). Depending on the amount and nature of aerosols, the effects on the convective atmospheric boundary-layer (CBL) evolution, structure and thermodynamics may differ significantly (Forster et al. 2007). More specifically, the CBL's heat budget and the surface fluxes are modified when radiation is scattered or absorbed, thus allowing less radiation to reach the surface (Charlson et al. 1992; Jacobson 1998; Raga et al. 2001; Yu et al. 2002; Liu et al. 2005; Li et al. 2007; Johnson et al. 2008; Malavelle et al. 2011). Extending previous studies, we address here the response of the CBL, driven by surface and entrainment fluxes, to aerosol heat absorption.

A proper calculation of the mean heating rates $(\overline{H R}$, henceforth only $H R)$ relies on the availability of both radiation and aerosol measurements. However, only a few observational campaigns have been based on a trustworthy database of both meteorological and air-quality data (Masson et al. 2008). The pioneering works of Zdunkowski et al. (1976) and Ackerman (1977) studied for the first time the impact of aerosol SW radiation absorption within the CBL. Zdunkowski et al. (1976) showed that $H R$ can locally be as high as $4 \mathrm{~K} \mathrm{~h}^{-1}$ but the overall effect of the polluting aerosol layer is a cooling of the lower CBL due to a reduced surface sensible heat flux. Since then, several studies have followed: Angevine et al. (1998) measured $H R$ in the lower troposphere of around 4-5 $\mathrm{K}_{\text {day }}{ }^{-1}$ for the FLATLAND series of experiments. Tripathi (2005) found via a field campaign in Kampur, located in urbancontinental India, that aerosol SW absorption leads to $H R \approx 1.8 \mathrm{~K} \mathrm{day}^{-1}$. Malavelle et al. (2011) found $H R$ associated with SW absorption in West Africa as high as $1.2 \mathrm{~K} \mathrm{day}^{-1}$, with $0.4 \mathrm{~K} \mathrm{day}^{-1}$ as a diurnal mean.

Where surface effects are concerned, Yu et al. (2002) showed that less solar radiation reaches the surface due to both aerosol backscattering and absorption, thereby suppressing the growth of the CBL. They also showed that aerosol heat absorption destabilises the upper CBL (see also Johnson et al. 2008).

With respect to the impact on the upper CBL, Ackerman (1977), and more recently Raga et al. (2001), have indicated that aerosols induce changes in the vertical structure of the CBL by redistributing heat and affecting the dynamics of the entrainment zone. Raga et al. (2001) found for Mexico City $H R$ of $20 \mathrm{~K} \mathrm{day}^{-1}$ when the absorbing aerosols are located in the upper CBL.

The impact of aerosols on the vertical structure of the CBL has been investigated by means of various methodologies: satellite data (Kaufman et al. 2002), observations made in experimental campaigns (Angevine et al. 1998; Johnson et al. 2008; Masson et al. 2008), numerical modelling (Cuijpers and Holtslag 1998; Yu et al. 2002) and combinations of these techniques (Liu et al. 2005; Wong et al. 2012). A process study on how aerosol heating by SW-absorbing aerosols influences the turbulent fluxes, surface forcing, vertical structure and heat budget of the CBL is still lacking, however.

The interaction between the turbulence and SW radiation, leading to upper CBL stabilization induced by the aerosol absorption of heat, is still not well understood, mainly due to (i) a scarcity of reliable measurements and (ii) a lack of high resolution three-dimensional simulations of the CBL that take the aerosol absorption effect into account. Facing all the limitations of measurements, especially in obtaining aerosol vertical profiles, high-resolution large-eddy simulation (LES) numerical experiments are the best available tool for a systematic study of the impact of absorption on the dynamics of the CBL. LES has been widely 
used to simulate turbulent flows in the atmosphere since it explicitly resolves large-scale turbulence and parametrizes the smaller eddies (Moeng 1984; Nieuwstadt and Brost 1986; Moeng and Wyngaard 1988; Sullivan et al. 1994).

We therefore take advantage of the capability of LES to investigate the CBL structure and to obtain a better understanding of the impacts of aerosol heat absorption on the CBL dynamics. We pay special attention to the quantification of the aerosol effects on the vertical structure of the CBL, focusing on its entrainment characteristics.

The paper is organized as follows: Section 2 describes the fundamental concepts of radiative transfer theory related to heat absorption. In Sect. 3 we explain the design of the numerical experiments and the models used. The aerosol absorption effects in disrupting the CBL's dynamics characteristics are described in Sect. 4. The impacts of aerosols on turbulent fluxes, horizontal velocities, potential temperature variances and CBL vertical structure are discussed in Sect. 5 and the results are summarized in Sect. 6.

\section{Theoretical Framework}

Here we describe the impact of the absorbing aerosols on the heat budget and their interaction with the turbulent field. We also introduce the necessary concepts of the radiative transfer theory used in this work. We use as a process illustration the 1D conservation equation of the potential temperature $\bar{\theta}$ for a horizontally homogeneous dry CBL (Stull 1988; Garratt 1992):

$$
\frac{\partial \bar{\theta}}{\partial t}=-\frac{\partial \overline{w^{\prime} \theta^{\prime}}}{\partial z}-w_{s} \frac{\partial \bar{\theta}}{\partial z}+\overline{H R} .
$$

Here the left-hand term in Eq. 1 expresses the potential temperature $(\bar{\theta})$ tendency within a well-mixed CBL. The first term on the right-hand side is the potential temperature turbulent vertical flux divergence, the second describes the vertical advection of potential temperature and the third is the radiation term (or heating rate). Based on radiative transfer theory (see Madronich 1987), the heating rate (in $\mathrm{K} \mathrm{s}^{-1}$ ) already integrated over the wavelength $(\lambda)$ can be calculated using either the convergence of the net radiative flux density $(\bar{F})$ or the total actinic flux $(\bar{\phi})$ and the aerosol layer absorption $\left(\sigma_{a}\right.$, in $\left.\mathrm{m}^{-1}\right)$. Both expressions read:

$$
\begin{aligned}
\overline{H R}_{F} & =\frac{1}{\rho c_{p}} \frac{\partial \bar{F}}{\partial z}, \\
\overline{H R}_{\phi} & =\frac{1}{\rho c_{p}} \sigma_{a} \bar{\phi}
\end{aligned}
$$

where $\rho$ is the air density, $c_{p}$ is the heat capacity.

Equation 2 has been used to calculate the heating rate as the divergence of the net radiative flux density between two vertical levels (Lilly 1968; Stull 1988; Garratt 1992; Duynkerke et al. 1995). Here, we are interested in the aerosol heating rates, $H R>0$, therefore we express it in terms of the convergence of the net radiative flux density. To calculate $H R$, Conant (2002) and Gao et al. (2008) used the actinic flux and the aerosol layer absorption efficiency, i.e. the amount of radiation absorbed by the aerosols within the layer, as described in Eq. 3. In both cases, the SW radiation absorbed by the aerosols is directly translated into heat when ideal thermal contact with the ambient air is assumed (Gao et al. 2008).

Both approaches are suitable since the data required by Eq. 2 are widely available (Angevine et al. 1998; Bretherton et al. 1999) and Eq. 3 is predominantly used in air-quality studies, e.g. photolysis rate calculations (Landgraf and Crutzen 1998; Stockwell and Goliff 
2004). Note that combined, Eqs. 2 and 3 relate the actinic flux to the divergence of net radiative flux density by the amount of absorbing aerosols within the layer (Madronich 1987; De Roode et al. 2001; Conant 2002). When there are no absorbing aerosol particles (i.e. $\sigma_{a}(\lambda)=0$ ), the net radiative flux density remains constant (see Madronich 1987; De Roode et al. 2001). However, when absorbing aerosols are present, radiation is absorbed within the layer, leading to warming. The interaction of aerosols with SW radiation is described by: (i) the single-scattering albedo $\omega_{0}(\lambda)$, (ii) the asymmetry factor $g$, and (iii) the optical depth $\tau(\lambda)$, (Liou 2002), where $\omega_{0}(\lambda)$ is defined as the ratio between the scattering and the extinction of radiation (therefore unitless). The asymmetry factor $g$ denotes the relative strength of forward scattering. For both Rayleigh and isotropic scattering, $g=0 . \tau(\lambda)$ is a unitless and integrated property of an atmospheric column and represents the degree to which aerosols prevent the transmission of light. Based on the radiative parameters discussed here, in Sect. 3 we design numerical experiments attempting to investigate the impact of light-absorbing aerosols on the dynamics of the CBL.

\section{Methodology}

\subsection{Model Description}

We study the response of turbulence to aerosol heat absorption by means of two different model approaches, LES and a mixed-layer (MXL) model, where the inversion layer is represented by an infinitesimal inversion-layer depth [zero-order jump model-(see Lilly 1968)]. Numerical experiments carried out with the LES technique enable us to understand the modifications to the state variables and calculate explicitly second-order moments in the CBL with aerosols. The LESs also enable us to investigate the impact of aerosol SW radiation absorption on the vertical structure of the CBL. Mixed-layer theory (zero- and first-order) is here employed to support the analysis and discussion of the LES results. With the zero-order MXL model we repeat the experiments as in the LES and derive expressions for boundary-layer height and inversion-layer strength equilibrium based on Lilly (1968) and Garratt (1992). By using the first-order mixed-layer equations (Betts 1974; Duynkerke et al. 1995; Sullivan et al. 1998; Van Zanten et al. 1999; Pino and Vilà-Guerau de Arellano 2008) we can investigate how the entrainment zone responds to the presence of absorbing aerosols.

The CBL time evolution change due to the aerosol heat absorption is also further analyzed. Isolating the effects of heat absorption within the CBL, and eliminating any other sources of disruption as far as possible, we perform all the analyses after reaching a boundary-layer depth in equilibrium. The conceptual/academic idea of studying a CBL in equilibrium is not new and has been used quite commonly in CBL studies (see Bretherton et al. 1999; VilàGuerau de Arellano and Cuijpers 2000). Our approach is inspired by the method used by (i) Lilly (1968) to investigate the role of longwave radiation in the development of shallow cumulus clouds, and by (ii) Tennekes (1973), in terms of experimental design and dynamics interpretation of a dry convective CBL, and by (iii) Bretherton et al. (1999), who studied entrainment by using an archetype boundary layer full of radiative active smoke and by simulating radiative cooling at the top of stratocumulus clouds.

To quantify the impact of the aerosols on the radiation field we use the 1D tropospheric ultraviolet and visible (TUV) radiative model (Madronich 1987). TUV calculates the net radiative flux density $(\bar{F})$ and actinic flux $(\bar{\phi})$ vertical profiles as functions of aerosol concentration and characteristics. As outlined above, the heating rates are calculated according 


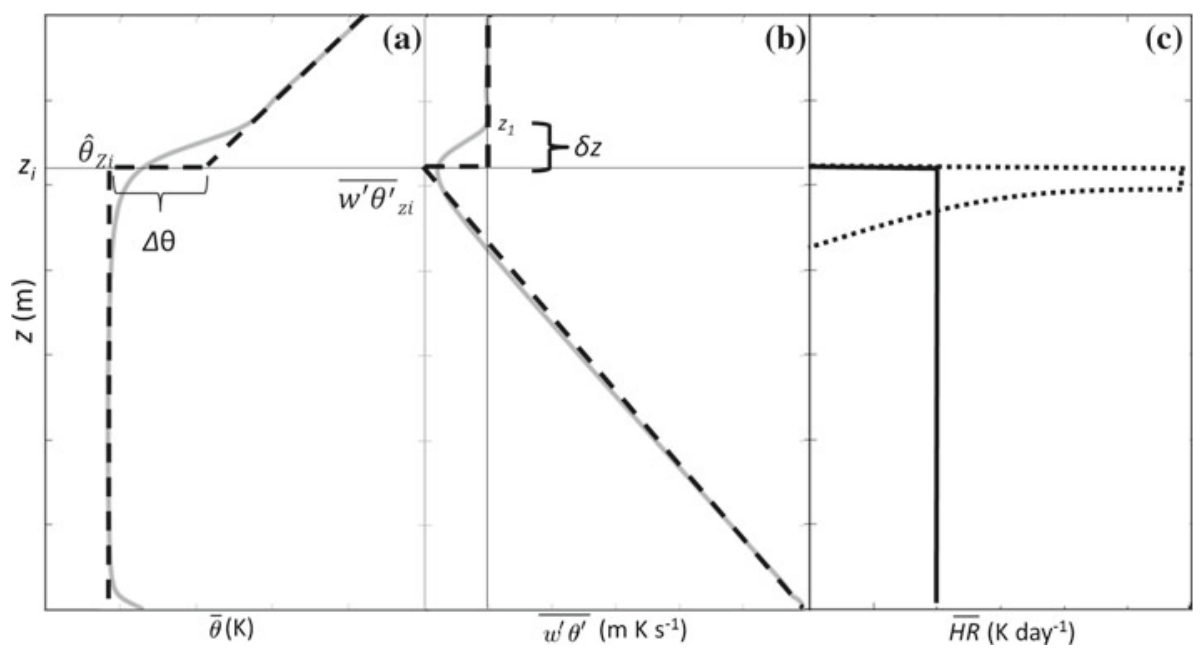

Fig. 1 Vertical profiles of a potential temperature, b buoyancy flux and $\mathbf{c} H R$ profiles when the heating rate is located at the top (dotted-line) or uniformly distributed in the CBL (continuous line). Here $\delta z$ is the entrainment depth $\left(\delta z=z_{1}-z_{i}\right)$, and $z_{i}$ is the boundary-layer height based on the minimum buoyancy flux and $z_{1}$ stands for the vertical level (above $z_{i}$ ) where the buoyancy flux first reaches zero. $\hat{\theta_{z i}}$ is the temperature and $\overline{w^{\prime} \theta_{z i}^{\prime}}$ the buoyancy flux at the $z_{i}$ level. In (a) and (b) the black-dashes represent the zero-order MXL approach and the grey continuous lines represent the LES

to Eqs. 2 and 3, and should be equivalent. We then prescribe the $H R$ vertical profiles in our LES.

Here we employ the Dutch atmospheric large-eddy simulation (DALES) model (Heus et al. 2010) to explicitly simulate the 3D structure of the CBL using vertical and horizontal high resolution and the interaction of turbulence with the heating rate due to aerosol SW radiation absorption. The parametrized eddies, solved by subgrid parametrizations, are determined by a filter that depends explicitly on the numerical grid size (see Sullivan et al. (1994) for details).

Figure 1 schematically presents the profiles of $\bar{\theta}$, sensible heat flux $\overline{w^{\prime} \theta^{\prime}}$ and $H R$. The dashed lines indicate the zero-order mixed-layer approach of the vertical profiles. Definitions such as boundary-layer height $\left(z_{i}\right)$, inversion-layer potential temperature jump $(\Delta \theta)$ and entrainment depth $(\delta z)$ (Betts 1974; Sullivan et al. 1998), used several times throughout this work, are also shown in Fig. 1.

The zero-order MXL model assumes a well-mixed CBL with constant vertical profiles of the state variables within the CBL (flux profiles are therefore linear). The entrainment zone (interface between the CBL and the free troposphere) is represented by an infinitesimal inversion layer (zero-order approach), i.e. $\delta z=0$ (Lilly 1968; Betts 1974). The MXL model expressions for the evolution in time of the potential temperature, inversion jump and CBL height, explicitly considering the impact of radiation absorption, are based on Garratt (1992). The equation for the temporal evolution of the potential temperature is the vertically integrated conservation equation for potential temperature (Eq. 1), considering explicitly the $H R$ term.

$$
\frac{\partial<\bar{\theta}>}{\partial t}=\frac{1}{z_{i}}\left({\overline{w^{\prime} \theta^{\prime}}}_{0}+w_{e} \Delta \theta\right)+\frac{1-r}{\rho c_{p}} \frac{\Delta F}{z_{i}}
$$




$$
\begin{gathered}
\frac{\partial \Delta \theta}{\partial t}=\gamma_{\theta} w_{e}-\frac{\partial<\bar{\theta}>}{\partial t} \\
\frac{\partial z_{i}}{\partial t}=w_{e}+w_{s}-\frac{r}{\rho c_{p}} \frac{\Delta F}{\Delta \theta}
\end{gathered}
$$

where $\left\langle\bar{\theta}>\right.$ is the bulk average potential temperature, $z_{i}$ is the boundary-layer height, $\overline{w^{\prime} \theta^{\prime}} 0$ is defined as the sensible heat flux at the surface, $w_{e}$ is the entrainment velocity, $\Delta \theta$ is the infinitesimal inversion-layer jump, $\Delta F$ (defined as positive) is the absorbed net radiative flux density, $r$ is the fraction of $\Delta F$ occurring immediately below the inversion layer, in analogy to the radiative cooling immediately above prescribed by Lilly (1968), $\gamma_{\theta}$ is the potential temperature lapse rate in the free troposphere, and $w_{s}$ is the subsidence velocity. To close the mixed-layer equation system (Eqs. $4 \mathrm{~b}$ and $4 \mathrm{c}$ ) the entrainment ratio $\beta_{w \theta}$ is defined as being constant and held equal to 0.2 (Stull 1988). Note that the $H R$ term is defined as being proportional to the divergence of the net radiative flux density, (i) over the whole CBL when $r=0$, or (ii) confined to the inversion layer when $r=1$.

As a first step we use the zero-order MXL model to derive simple relations that explicitly take heat absorption into account, for CBL height and the inversion-layer jump. Our primary aim is to determine how the aerosol absorption of SW radiation perturbs a CBL in equilibrium. We define the equilibrium as $\frac{\partial z_{i}}{\partial t}=\frac{\partial \Delta \theta}{\partial t}=0$ (note $\frac{\partial<\theta>}{\partial t} \neq 0$ ), in order to isolate the aerosol SW absorption from other physical mechanisms, such as diurnal variations. Therefore, we analyze our results after the CBL has reached equilibrium between entrainment and subsidence velocities.

Using Eqs. $4 \mathrm{a}-4 \mathrm{c}$ under equilibrium conditions, we found the following expressions for both $z_{i}$ and $\Delta \theta$ :

$$
\begin{gathered}
z_{i}=\frac{1}{\gamma\left|w_{s}\right|}\left[\overline{w^{\prime} \theta_{0}^{\prime}}\left(1+\beta_{w \theta}\right)+(1-r) \frac{\Delta F}{\rho c_{p}}\right], \\
\Delta \theta=\frac{1}{\left|w_{s}\right|}\left[\beta_{w \theta} \overline{w^{\prime} \theta_{0}^{\prime}}-r \frac{\Delta F}{\rho c_{p}}\right] .
\end{gathered}
$$

The boundary-layer height and inversion-layer jump solutions thus depend on, (i) the sensible heat flux at the surface, (ii) the entrainment rate, (iii) the stability of the free atmosphere, as seen only in Eq. 5a, (iv) the vertical distribution of the absorbing aerosols, (v) the absorbed net radiative flux density, and (vi) the subsidence velocity.

As a next step, we use LES to investigate how the boundary-layer turbulent structure is modified by the presence of SW absorbing aerosols in a dry CBL.

\subsection{Design of Numerical Experiments}

We consider a dry, shearless and non-chemical reactive CBL in equilibrium integrated for $30 \mathrm{~h}$ to ensure steady-state. By simulating an idealized boundary layer in equilibrium, we are able to study how the balance of the entrainment (promoting growth) and subsidence (suppressing growth) is perturbed only by the aerosol absorption rather than other possible physical mechanisms (such as radiation scattering). Our experiments are designed to study systematically: (i) the decreased sensible heat flux at the surface, and (ii) the modifications of the entrainment zone due to aerosol heat absorption. Special attention is paid to the vertical structure of the CBL, turbulent transport and heat budget modifications. The initial and boundary conditions of our LES experiments are described in Table 1. We kept the design of the MXL model experiments as close as possible to the LES. Despite the nonapplicable vertical and horizontal resolutions for the MXL model, the only difference lies in 
Table 1 Initial and prescribed values used for DALES, MXL and TUV (aerosol properties) models for the CONTROL, CONTROL-SH, UNI and TOP experiments

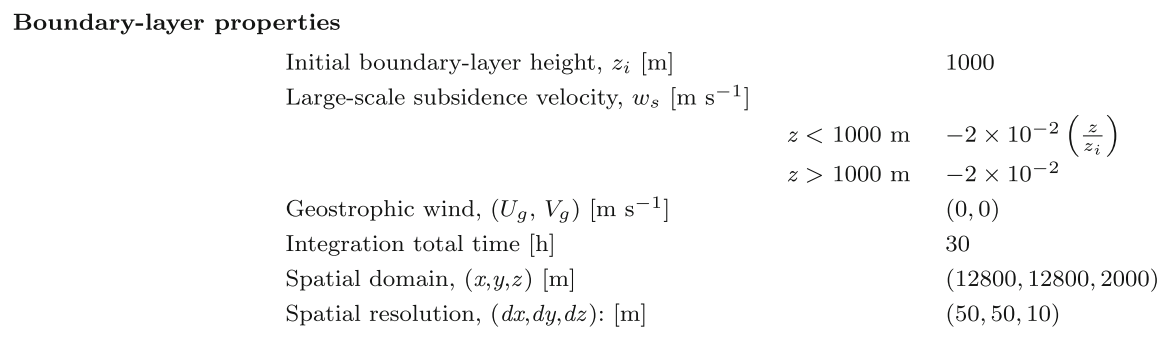

Heat

Surface sensible heat flux, $\overline{w \theta}_{0}\left[\mathrm{~K} \mathrm{~m} \mathrm{~s}^{-1}\right]$

$\begin{aligned} \text { CONTROL } & 0.1 \\ \text { CONTROL-SH } & 0.08 \\ \text { UNI } & 0.08 \\ \text { TOP } & 0.08\end{aligned}$

Potential temperature profile $[\mathrm{K}]$

\begin{tabular}{cccc}
\multicolumn{2}{c}{ DALES } & \multicolumn{2}{c}{ MXL } \\
$z<1000 \mathrm{~m}$ & 288.0 & $z<1000 \mathrm{~m}$ & 288.0 \\
$1000 \mathrm{~m}<z<1010 \mathrm{~m}$ & $288.0+10^{-1} z$ & & - \\
$z>1010 \mathrm{~m}$ & $289.0+6 \times 10^{-3} z$ & $z>1000 \mathrm{~m}$ & $289.0+6 \times 10^{-3} z$
\end{tabular}

Aerosol properties

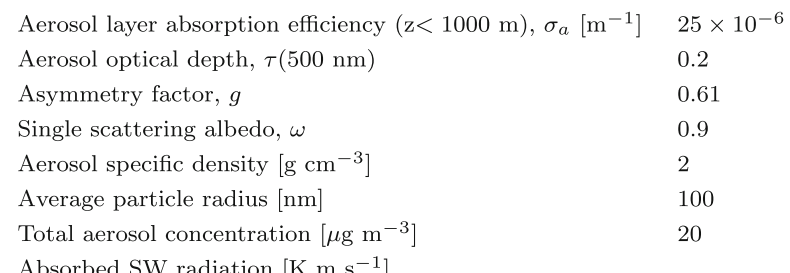

CONTROL $\quad 0.0$

CONTROL-SH $\quad 0.0$

UNI 0.02

TOP $\quad 0.02$

All the properties except CBL height and the potential temperature are kept constant during the simulations. The subscripts 0 and $i$ indicate values at the surface and the entrainment zone, respectively

the infinitesimal inversion-layer depth (Table 1: heat) if compared to the finite value prescribed in our LES.

The numerical experiment "CONTROL" simulates a clear CBL (i.e. no absorbing aerosols) in equilibrium driven only by sensible heat flux at the surface. The experiments "UNI" (urban average UNIform aerosol concentration) and "TOP" simulate the same boundary-layer properties as in CONTROL but locating an aerosol layer (i) uniformly within the CBL for UNI, and (ii) located at the upper $200 \mathrm{~m}$ of the CBL for TOP (Fig. 1c). The experiment CONTROL-SH is identical to the CONTROL case (i.e. no absorbing aerosols) but with the same sensible heat flux as in UNI and TOP. Doing so, enables us to isolate the 

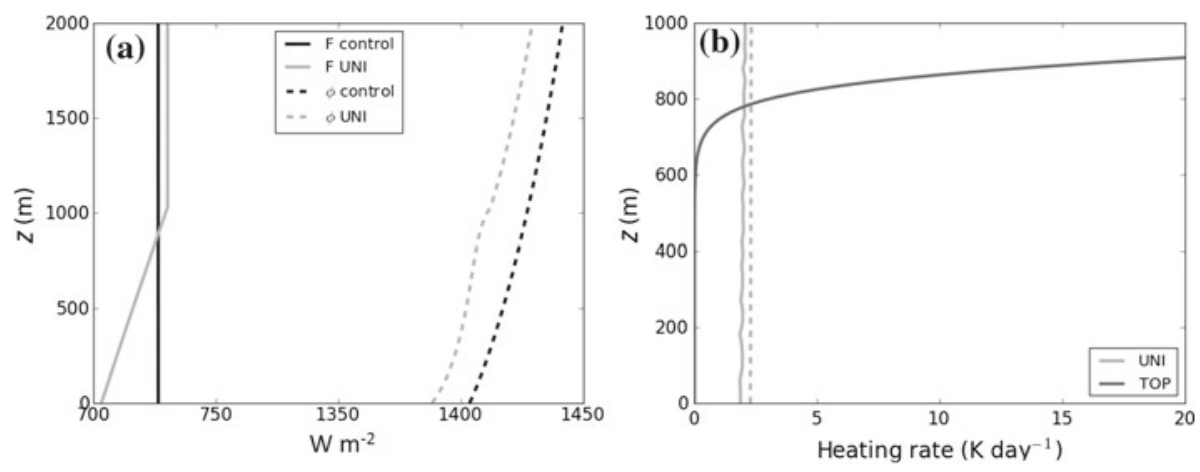

Fig. 2 a Profiles of the net radiative flux density (continuous lines) and actinic flux (dashed lines); b the respective $H R$ vertical profiles. In (b) the continuous line for UNI represents the heating rate calculated based on the net radiative flux density divergence (Eq. 2). The dashed line is the heating rate based on actinic flux and aerosol layer absorption efficiency (Eq. 3). Note that the heating rate obtained for the TOP experiment is based on the exponential decay. To improve visualization, the vertical scale is different and the HR peak (25 $\mathrm{K} \mathrm{day}^{-1}$ ) for the TOP case is not shown

effect of the surface heat flux on the CBL dynamics. Notice that the CONTROL-SH experiment mimics a boundary layer where the surface heat flux decreases by the same amount as in UNI and TOP, assuming a clear CBL.

In UNI and TOP, the shadowing effect at the surface due to aerosol absorption is taken into account by reducing the sensible heat flux at the surface by the same amount as the heat absorbed within the CBL. Thus, both the UNI and TOP experiments are comparable to CONTROL, since the total heat introduced in the system always remains constant. The total heat input $(H I)$ in $\mathrm{m} \mathrm{K} \mathrm{s}^{-1}$ reads:

$$
H I=\overline{w^{\prime} \theta_{0}^{\prime}}+\int_{0}^{z_{i}} \overline{H R} d z
$$

where $\int_{0}^{z_{i}} \overline{H R} d z=0$ for the CONTROL case. We thus ensure that the three numerical experiments are energy consistent and that the impact on the CBL dynamics is due to the amount and vertical distribution of the aerosols.

We use the TUV model to obtain realistic vertical profiles of actinic flux and net radiative flux density for the CONTROL and UNI experiments and then calculate the atmospheric heating rate by means of Eqs. 2 and 3. The specified aerosol properties $\tau, \omega_{0}, g$ (Table 1) in TUV are based on previous studies, and are representative of an urban, moderately polluted CBL (Raga et al. (2001); Yu et al. (2002) and references therein; Hewitt and Jackson (2009)). The molecular absorption of $\mathrm{O}_{3}$ and $\mathrm{NO}_{2}$ is not considered. The TUV model maximum wavelength range integration $\lambda[230-1000] \mathrm{nm}, \delta \lambda=2 \mathrm{~nm}$ and vertical resolution $\Delta z=30$ $\mathrm{m}$ are used. The surface albedo is 0.2 . No radiative transfer code is used to calculate $H R$ for the TOP experiment. Instead, similar to Bretherton et al. (1999), we integrate the HR profile obtained for the UNI case and place the total heat in the upper $200 \mathrm{~m}$ of the CBL by using an exponential decay with a maximum at the top of the CBL. By doing so, we ensure that the amounts of energy absorbed in UNI and TOP are the same.

Figure 2 shows the radiation fields calculated by TUV and the subsequent $H R$ calculated based on Eqs. 2 and 3 for UNI and on the exponential decay for the TOP experiment. 
The constant net radiative flux density vertical profile shows that no SW absorption takes place either in the free atmosphere and within the CBL for CONTROL (see Eq. 2). Within the CBL, in the UNI experiment the absorbing aerosols linearly reduce the net radiative flux density at the surface by about $20 \mathrm{Wm}^{-2}$, in agreement with the values obtained by Yu et al. (2002) for similar aerosol properties. Rayleigh scattering is responsible for the slightly diminished actinic flux (dashed lines) towards the surface. The smaller $\phi$ observed in UNI is caused by the SW absorption throughout the CBL. Since there are no aerosols in the free atmosphere (i.e. $\sigma_{a}=0$ above $1000 \mathrm{~m}$ ) the net radiative flux density profiles are constant in height.

In Fig. $2 b$ we observe that the absorption of SW radiation by aerosols significantly heats the CBL by $1.8 \mathrm{~K} \mathrm{day}^{-1}$, uniformly distributed for the UNI case and by about $25 \mathrm{~K} \mathrm{day}^{-1}$ at $z=1000 \mathrm{~m}$ (peak not shown) when concentrated at the upper CBL (for TOP experiment). It is important to mention that $H R$ calculated based on the net radiative flux density divergence (Eq. 2) and the total actinic flux (Eq. 3) for the UNI case (dashed and full-light grey lines in Fig. 2b) are equivalent. Since meteorological and air-quality experiments are not designed with the same aim in mind (Bierwirth et al. 2010; Wong et al. 2012), synchronized and reliable measurements of net radiative flux density and actinic flux are difficult to obtain. The results showed in Fig. $2 \mathrm{~b}$ open an alternative path to the $H R$ calculation by using two different radiative quantities. The slightly larger $H R$ observed in the calculation based on the actinic flux profile is due to the assumed constant aerosol absorption coefficient within the CBL (see Angevine et al. 1998). Moreover, the TUV model integrates the wavelength only up to $1000 \mathrm{~nm}$, missing therefore a part of the solar spectrum. This assumption should only affect the actinic flux results since in the net flux density approach we are interested in the divergence of the flux canceling any contribution.

The $H R$ profiles are comparable to previous work: Raga et al. (2001) with a similar setup as the one used in the TOP experiment found $H R$ as large as $30 \mathrm{~K} \mathrm{day}^{-1}$ supported by observations in Mexico City. In the UNI case, $H R$ is comparable to the results of Angevine et al. (1998); Jochum et al. (2004) and Tripathi (2005), who found $4 \mathrm{~K} \mathrm{day}^{-1}, 6 \mathrm{~K} \mathrm{day}^{-1}$ and $2 \mathrm{~K}$ day $^{-1}$ respectively. The $H R$ values obtained for both UNI and TOP experiments are prescribed in our LES.

\section{Effects of Aerosol Heat Absorption on the CBL Characteristics}

We start by studying the CBL height and entrainment zone responses to the aerosol heat absorption. Table 2 summarizes the main CBL characteristics for the three experiments after $30 \mathrm{~h}$ of LES.

In Table $2, \delta z$ is the entrainment depth $\left(\delta z=z_{1}-z_{i}\right.$, see Fig. 1$)$, where $z_{i}$ is the boundarylayer height based on the minimum buoyancy flux and $z_{1}$ is the vertical level (above $z_{i}$ ) at which the buoyancy flux first reaches zero. $R i_{\delta}$ is the bulk Richardson number calculated for the entrainment zone (Sullivan et al. 1998), where

Table $2 \mathrm{CBL}$ properties after $30 \mathrm{~h}$ of simulation; $w_{*}$ is the convective velocity scale, and $R i_{\delta}$ is the bulk Richardson number at the entrainment zone

\begin{tabular}{|c|c|c|c|c|c|c|}
\hline Case & $w_{*}\left(\mathrm{~m} \mathrm{~s}^{-1}\right)$ & $z_{i}(\mathrm{~m})$ & $\Delta \theta(\mathrm{K})$ & $\delta z(\mathrm{~m})$ & $R i_{\delta}$ & $\beta_{w \theta}$ \\
\hline Control & 1.50 & 1040 & 1.1 & 110 & 15.0 & 0.16 \\
\hline UNI & 1.38 & 955 & 0.61 & 130 & 11.3 & 0.14 \\
\hline TOP & 1.34 & 860 & 0.1 & 210 & 1.61 & 0.14 \\
\hline
\end{tabular}




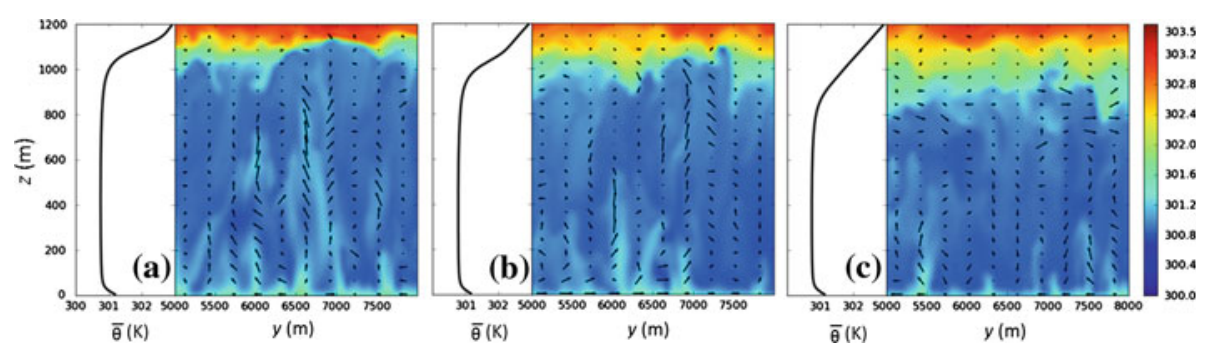

Fig. 3 1-h Slab averaged potential temperature $\bar{\theta}$ and $y-z$ cross-sections of the $\theta$ field for experiments a CONTROL, b UNI and c TOP after $30 \mathrm{~h}$ of simulation. The arrows represent the instantaneous wind field $\left(\mathbf{V}, w^{\prime}\right)$. To improve visualization we show only a sub-part of the horizontal domain (y) 5000-8000 m. Note that due to the cycle boundary conditions and horizontal homogeneity the cross-section location in the $x$-direction is arbitrary

$$
R i_{\delta}=\alpha \Delta \theta \frac{z_{i}}{w_{*}^{2}}
$$

and $\alpha$ is the buoyancy parameter. We see from Table 2 that the aerosol absorption of SW radiation makes the ABL shallower by 8.2 and $17.3 \%$ for the UNI and TOP simulations respectively. Moreover, in UNI and TOP, the potential temperature jump is weaker and the entrainment zone is deeper and less stable. The entrainment ratio for UNI and TOP experiments is equally decreased $(12.5 \%$ ) compared to the CONTROL experiment, which identifies the surface flux as the driving mechanism controlling the entrainment rate. By focusing on the depth of the entrainment zone, we find that the aerosol heat absorption, besides destabilizing (decreasing $R i_{\delta}$ ), also deepens the entrainment zone (EZ) by 18 and $91 \%$ in UNI and TOP respectively. Since the effects are more pronounced in the TOP experiment, the stability and depth of the entrainment zone depend not only on the amount of aerosols, but also on their vertical distribution. Accordingly, the combination of processes indicates that the aerosol heat absorption has a significant effect on both the surface and the entrainment zone. Further analysis of the CBL vertical structure is therefore needed for an understanding of the changes in the turbulent field caused by the absorption of heat within the CBL (Fig. $2 \mathrm{~b}$ ). Figure 3 shows the instantaneous profiles of the potential temperature calculated by LES, where the arrows represent the wind vector in the CBL. In the left-hand side of each figure we also plot the 1-h horizontally-averaged potential temperature.

The lighter colours within the CBL highlight thermals transporting warmer air, therefore ascendant motion (see wind field), while the darker zones show the subsidence motion. The intensity of the vertical movements is more pronounced for the CONTROL case. The diminution in the vertical motion magnitude between CONTROL (maximum $2.4 \mathrm{~m} \mathrm{~s}^{-1}$ ), UNI (maximum $2.0 \mathrm{~m} \mathrm{~s}^{-1}$ ) and TOP (maximum $1.6 \mathrm{~m} \mathrm{~s}^{-1}$ ) is explained by the shadowing effect at the surface by the aerosol SW radiation absorption. Since less sensible heat flux is prescribed for UNI and TOP the turbulent kinetic energy (TKE) is also reduced. This will be discussed in detail in the next section. Even though the effect of the smaller surface heat flux for UNI and TOP explains the reduced vertical motions this is not sufficient to enable us to understand all the observed changes. Comparing the UNI and TOP experiments (both with identical surface heat fluxes) we find weaker thermals and updrafts/downdrafts for the latter. We also observe that for TOP the vertical motions are weakened throughout the CBL while in CONTROL and UNI this occurs mostly at higher levels. This indicates a combined effect changing not only the surface heat flux but also the atmospheric structure (as suggested by Ackerman (1977) and Raga et al. (2001)). The earlier potential temperature 

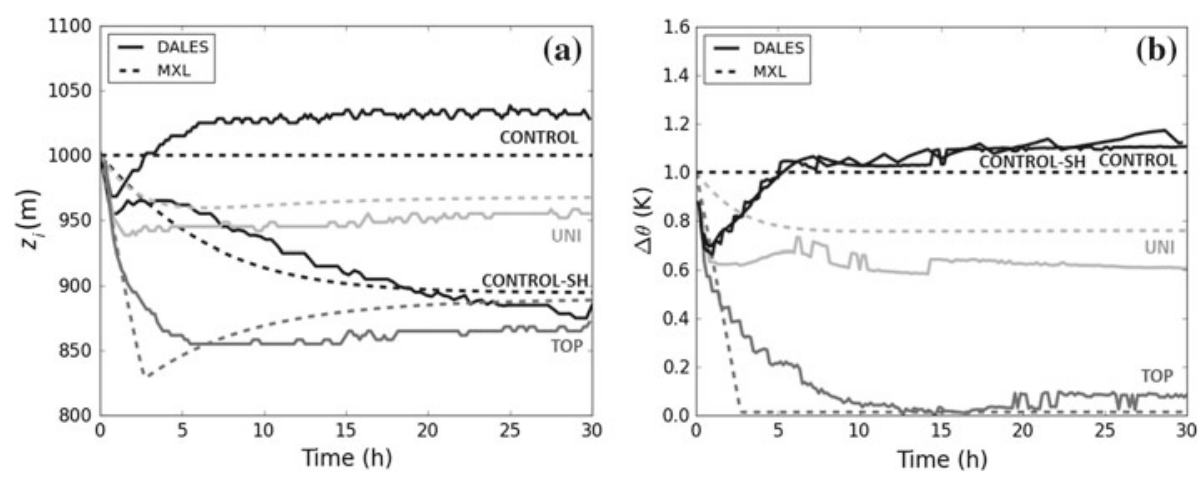

Fig. 4 Evolution of a CBL height and $\mathbf{b}$ inversion-layer jump. The continuous lines indicate LES and the dashed lines MXL results

stabilization ( $\bar{\theta}$ vertical profile) in the vicinity of the entrainment zone observed for UNI, and more significantly for TOP, is explored in detail in Sect. 5.

Figure 4 shows the approach to equilibrium of the boundary-layer height and potential temperature inversion jump calculated using the DALES and MXL models. We observe that UNI and CONTROL reach the equilibrium situation for both CBL height and potential temperature inversion jump 2-3 h earlier than TOP. This is explained by the already wellmixed aerosol initial profile in UNI and the absence of aerosols in CONTROL. The aerosol layer in the TOP experiment disturbs the inversion-layer jump more strongly (Fig. 4b), which means that more time is needed to reach a new equilibrium state. The MXL model results are comparable to the LES in all cases. The satisfactory agreement enables us to provide a mathematical/physical interpretation of the results (Eqs. 5a and 5b).

As Fig. 4a shows, we find that the CBL depth is smaller in both the UNI (955 m) and TOP $(860 \mathrm{~m})$ experiments, agreeing with the findings of Yu et al. (2002) and Wong et al. (2012). Equation 5a predicts that, in the absence of the absorption of heat (no aerosols, $\Delta F=0$ ) and with the same atmospheric conditions (subsidence and free atmospheric stability), the CBL depth depends only on the surface heat flux and the entrainment rate, in the absence of other large-scale forcing. Since $r=1$ for the TOP experiment, Eq. 5a has the same solution for both CONTROL-SH $(\Delta F=0)$ and TOP (as also shown in Fig. 4a). The CONTROLSH experiment has less total energy within the system but the same subsidence profile as CONTROL, which means that equilibrium is reached at a later stage. The MXL model also reproduces CONTROL-SH. The different MXL model solutions, depending on where the heat absorption occurs, show that the effects of the aerosol absorption depend not only on the amount (affecting $\Delta F$ ) but also on the vertical distribution $(r)$ of aerosols.

Figure $4 \mathrm{~b}$ shows the temporal evolution of the potential temperature inversion-layer jump. The $\Delta \theta$ temporal evolution for CONTROL-SH follows the CONTROL experiment, as Eq. $5 \mathrm{~b}$ also shows. Note that we define $\Delta \theta$ as the difference between the average potential temperature from the surface until $z_{i}$ and a linear extrapolation from the free atmosphere potential temperature lapse rate to the same level (see Fig. 1a). Since the potential temperature inversion-layer jump is smaller in TOP $(0.1 \mathrm{~K})$ than UNI $(0.6 \mathrm{~K})$, a priori the entrainment zone is less stable (see Table 2) and should lead to a deeper CBL. However, the weakening of the potential temperature inversion jump does not lead to an increase in the depth of the CBL (Fig. 4a). Rather, the CBL becomes shallower when $\Delta \theta$ is smaller. This apparent contradiction indicates that the aerosol layer at the top of the CBL, besides reducing the 
potential temperature jump, stabilizes the lower layers by extending the inversion depth (see Fig. 3c). Zdunkowski et al. (1976), Ackerman (1977), Jacobson (1998) and Raga et al. (2001) have already described this effect but were unable to quantify it explicitly. In the next section we investigate the vertical structure of the $\mathrm{CBL}$ and the entrainment zone in more detail.

\section{Impact of Aerosol Heat Absorption on the Entrainment Zone}

The aerosol absorption of SW radiation changes both the surface and the EZ. Here we focus on the response of the dynamics to the aerosol heat source in the upper CBL and in the entrainment zone. The cross-sections in Fig. 3 have already shown that the temperature and wind fields change depending on the vertical distribution of the aerosols. We therefore first investigate the atmospheric stability below the EZ by calculating the horizontally-averaged potential temperature anomaly and characterize its strength by the squared Brunt-Väis $\ddot{a} l \ddot{a}$ frequency $\left(N^{2}\right)$,

$$
N^{2}=\alpha \frac{\partial \bar{\theta}}{\partial z}
$$

The potential temperature anomaly profile is defined as $\theta^{\prime}=\bar{\theta}-<\bar{\theta}>$, where $<\bar{\theta}>$ is the bulk average potential temperature (see Eq. 4a). The results are presented in Fig. 5.

A significantly earlier rise of $\theta^{\prime}$ and $N^{2}$ for the UNI and TOP experiments is found, corroborating the lower CBL stratification observed in Fig. 3. In Fig. 5a, the deepening of the entrainment zone depth for UNI and TOP (see also Table $2, \delta z$ ) can also be seen. The $\langle\bar{\theta}>$ is independent of the aerosol absorption of heat in all the experiments, showing that our simulations conserve energy. As already indicated by the different values of the Richardson number (Table 2), $N^{2}$ indicates a less stable stratified EZ in the TOP experiment (Fig. 5b). The $N^{2}$ profiles reach the same value in the free atmosphere, since $\frac{g}{\theta_{0}} \gamma=2 \times 10^{-4} \mathrm{~s}^{-2}$ for the three experiments. The $N^{2}$ peak at the entrainment zone is not observed for the TOP experiment because of the smaller $\Delta \theta$ (Fig. 4b) leading to a less stable entrainment zone. Moreover, $N^{2}=0$ below $600 \mathrm{~m}$ (not shown) since the layer is well-mixed.
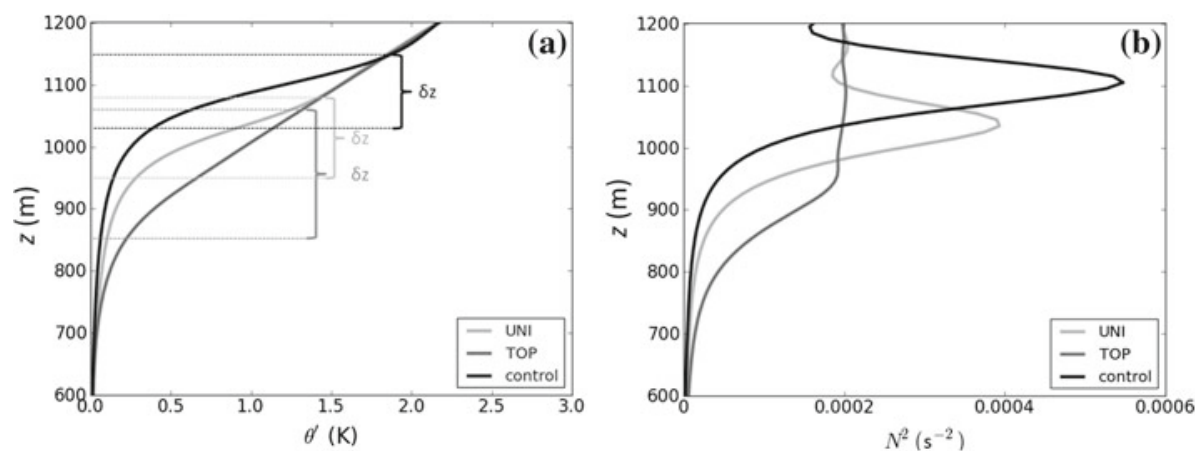

Fig. 5 Vertical profiles of the last-hour horizontally averaged a potential temperature anomaly, and b squaredBrunt-Väisälä frequency. In (a) we also identify the entrainment zone depth. To improve visualization, $\theta^{\prime}$ and $N^{2}$ are shown only from 600 to $1200 \mathrm{~m}$ 
Table 3 Heat budget at the EZ. Individual contributions (absolute and relative-in \% ) of each term in Eq. 10 are calculated by the LES for the last hour of simulation

\begin{tabular}{lllllll}
\hline & $\beta_{w \theta}(\%)$ & $\beta_{\delta z}(\%)$ & $\beta_{H R}(\%)$ & $n$ & $\left.\frac{w_{e}}{w *}\right|_{\text {DALES }}$ & $\frac{\left(\beta_{w \theta}+\beta_{\delta z}-\beta_{H R}\right)}{R i^{n}}$ \\
\hline Control & $-0.16(55.2)$ & $0.13(44.8)$ & - & 1.1 & 0.014 & 0.015 \\
UNI & $-0.14(40)$ & $0.17(48.6)$ & $0.04(11.4)$ & 1.2 & 0.015 & 0.015 \\
TOP & $-0.14(23.0)$ & $0.28(45.9)$ & $0.19(31.1)$ & 5.5 & 0.015 & 0.017 \\
\hline
\end{tabular}

\subsection{Heat Budget of the Entrainment Zone}

The main differences among the experiments lie in the changes in the EZ vertical structure caused by the aerosol heat absorption. However, the LES results indicate that the minimum of the entrainment flux $\left(\beta_{w \theta}=0.14-0.16\right)$ and average entrainment velocity $\left(20 \mathrm{~mm} \mathrm{~s}^{-1}\right)$ are similar in all the three experiments. In turn, an increased EZ depth can be observed for the UNI and TOP experiments (see Table 2).

Since the inversion-layer depth becomes relevant to our analysis we use the first-order mixed layer (1-MXL) theory, in which a finite entrainment depth is assumed instead of an infinitely small depth, to support the LES data interpretation. The 1-MXL model was used earlier by Sullivan et al. (1998) and Pino and Vilà-Guerau de Arellano (2008) for the same purpose. The entrainment heat budget expression for the 1-MXL considering radiation absorption is derived after vertically integrating the heat conservation equation (Betts 1974; Sullivan et al. 1998; Van Zanten et al. 1999; Pino and Vilà-Guerau de Arellano 2008),

$$
w_{e} \Delta \theta=\overline{w^{\prime} \theta_{z_{i}}^{\prime}}+\delta z \frac{\partial \hat{\theta_{z i}}}{\partial t}-\int_{z_{i}}^{z_{1}} \overline{H R} d z .
$$

Betts (1974) first presented the equation without considering the radiation contribution (last term in the right-hand side), but Van Zanten et al. (1999) later incorporated $H R$ in terms of the divergence of net radiative flux density to study longwave radiative cooling of stratocumulus clouds. Here, for the first time, we apply it in terms of the integral of the heating rate within the entrainment depth.

Following the derivation of Betts (1974), and taking the radiation term into account as in Van Zanten et al. (1999), and using the same methodology as suggested by Sullivan et al. (1998), we can conveniently re-write Eq. 9 in terms of the bulk Richardson number defined in Eq. 7:

$$
\frac{w_{e}}{w_{*}}=\frac{\left(\beta_{w \theta}+\beta_{\delta z}-\beta_{H R}\right)}{R i_{\delta}^{n}}
$$

where $\beta_{w \theta}=\overline{w^{\prime} \theta_{z_{i}}^{\prime}} / \overline{w^{\prime} \theta_{0}^{\prime}}, \beta_{\delta z}=\left(\delta z \frac{\partial \hat{\theta}}{\partial t}\right) / \overline{w^{\prime} \theta_{0}^{\prime}}, \beta_{H R}=\int_{z_{i}}^{z_{1}} \overline{H R} d z / \overline{w^{\prime} \theta_{0}^{\prime}}$ and " $n$ " is the Richardson number's power-law index as proposed by Fernando (1991) and used by Pino and Vilà-Guerau de Arellano (2008). This notation is convenient since it enables us to investigate the effects of the surface heat flux $\left(\beta_{w \theta}\right)$, entrainment depth $\left(\beta_{\delta z}\right)$ and SW radiation absorption $\left(\beta_{H R}\right)$ calculated by the LES individually. Table 3 shows the contribution of each term to the entrainment heat budget (Eq. 10).

Despite the slight reduction observed in the absolute entrainment rate of UNI and TOP (0.16-0.14) its relative importance to the heat budget significantly decreases from around 55 to $23 \%$. Moreover, the term that includes the dependence of the EZ depth is significant for 

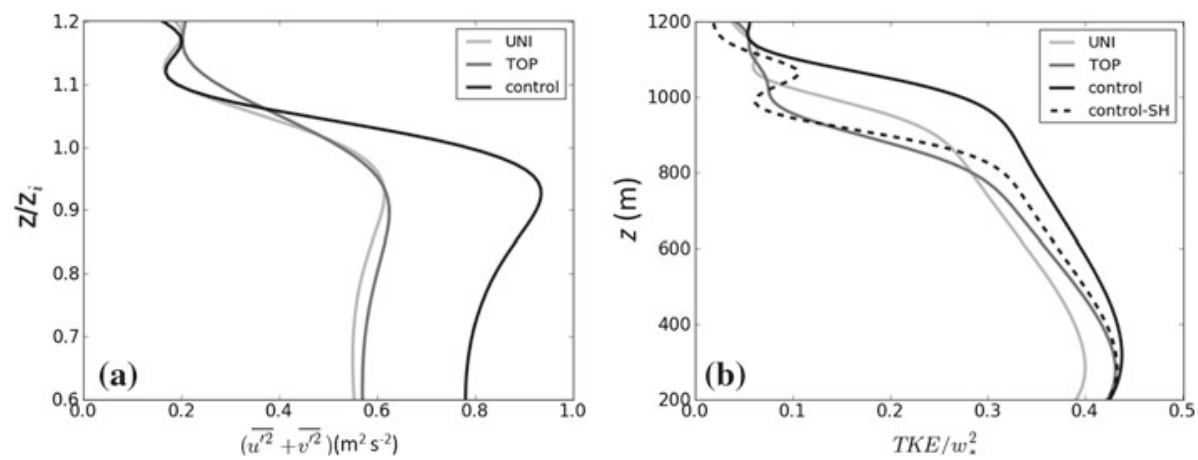

Fig. 6 Vertical profiles of the last-hour horizontally averaged a horizontal velocity variance and $\mathbf{b}$ normalized turbulent kinetic energy for CONTROL, UNI, TOP and CONTROL-SH (only for TKE). To focus more clearly on the upper CBL characteristics, the horizontal velocity variance is shown from $(0.6-1.2) z / z_{i}$

all the experiments, being $45-49 \%$ of the total contribution to the entrainment heat budget (Sullivan et al. 1998; Van Zanten et al. 1999). However, the absolute value increases in the TOP experiment, indicating a wider EZ (see $\delta z$ in Table 2 and Fig. 5). The $\beta_{H R}$ term in UNI and TOP represents respectively 11 and $31 \%$ of the total contribution to the entrainment heat budget. This increased $\beta_{H R}$ contribution for TOP is to be expected, since the aerosol heating is concentrated in the upper CBL. The index values $(n)$ in Eq. 10 in CONTROL and UNI agree well with those proposed by Pino and Vilà-Guerau de Arellano (2008). For the TOP case, the potential temperature inversion jump is drastically reduced $(0.1 \mathrm{~K}$, Fig. $4 \mathrm{~b})$, resulting in a different $n=5.5$. Fernando (1991) and Sullivan et al. (1998) have already pointed out that $R i<14$ needs a different power-law index. The TOP results also indicate a deeper EZ due to the major contribution of the aerosol heat absorption term $\left(\beta_{H R}\right)$ to the EZ heat budget.

The last two columns in Table 3 refer to the comparison of the Eq. 10 right- and left-hand sides calculated independently with the LES. The agreement for all the cases shows that 1MXL theory satisfactorily explains the changes in the EZ heat budget when aerosol absorption takes place. Heat absorption may therefore be as important as entrainment deepening in the EZ heat budget. High-resolution models like LES are needed to accurately calculate the gradients in the entrainment zone and to properly quantify the effect of aerosol heat absorption.

\subsection{Entrainment Zone High-order Statistics}

We have observed that aerosol heat absorption (i) weakens the potential temperature jump, and (ii) deepens the EZ. Here we investigate the second-order statistical moments for velocity and temperature to further quantify the impact of aerosol heat absorption.

Figure 6 shows the vertical profiles of the horizontal velocity variances and the turbulent kinetic energy for the three cases under study. Figure 6a shows typical values for a CBL (Sullivan et al. 1998). Close to the top of the CBL, however, the gradients of the horizontal velocity variance are different due to the modifications in the EZ depth and potential temperature inversion jump. The horizontal variance maximum observed in the CONTROL experiment between $0.8<z / z_{i}<1.0$ indicates a transfer from vertical to horizontal motions when the updrafts encounter the strong inversion layer (see also Fig. 3a). The same behaviour (though less intense) is observed in UNI. In TOP, the decreased potential temperature jump and the deeper entrainment zone lead to a weaker variance onset since less momentum 


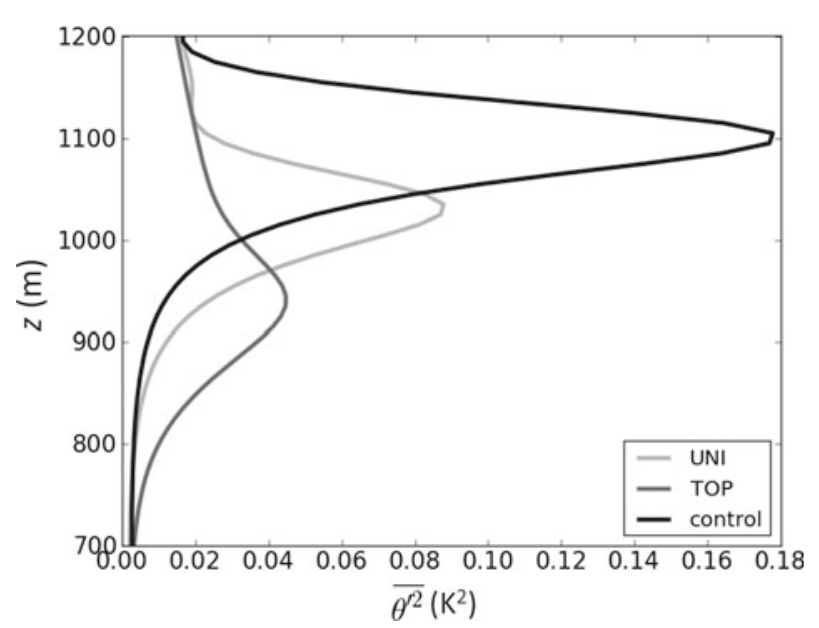

Fig. 7 Vertical profiles of the last-hour horizontally-averaged $\bar{\theta}$ variance. In order to focus more clearly on the upper CBL characteristics, the potential temperature variance is shown from 700 to $1200 \mathrm{~m}$

is transferred from the updrafts (Sullivan et al. 1998). We quantify the ratio of the vertical velocity variance to the horizontal one, $\frac{\overline{w^{\prime 2}}}{\overline{u^{\prime 2}}+\overline{v^{\prime 2}}}$, to determine the degree of anisotropy in the CBL. Our results show less pronounced vertical motions in TOP (0.42) than in the CONTROL (0.50) and UNI (0.49) experiments, indicating a greater conversion of vertical into horizontal motions within the CBL (see also Fig. 3c).

In Fig. $6 \mathrm{~b}$ we show the dimensionless TKE vertical profile for all the experiments also including CONTROL-SH to bring out the contribution of the reduced surface sensible heat flux to the TKE profile. Since our intention is to compare the different TKE vertical structures, this figure is not normalized by $z_{i}$. For TOP, closer to the surface the TKE behaviour is totally explained by the surface heat forcing (the TKE profile follows CONTROL-SH). However, above $z \approx 400 \mathrm{~m}$ the TKE vertical profile for TOP shows a steeper decrease compared to CONTROL-SH, indicating that the CBL vertical structure is altered. The physical explanation is as follows: in the cases of CONTROL and UNI, the updrafts find less resistance than in TOP to raise within the mixed layer and reach the EZ.

The modifications of the EZ characteristics are further quantified with an analysis of the potential temperature variance. Figure 7 presents the vertical $1-\mathrm{hr}$ average $\overline{\theta^{\prime 2}}$ profile. The $\overline{\theta^{\prime 2}}$ maximum for the three experiments is found within the EZ. The earlier onset of the $\overline{\theta^{\prime 2}}$ for UNI and TOP experiments corroborates the lower stratification observed in $\theta^{\prime}$ and $N^{2}$ profiles (Fig. 5). The aerosol heat absorption affects the magnitude of the $\bar{\theta}$ variance by reducing it by 47 and $75 \%$ in UNI and TOP respectively. The weaker potential temperature jump leads to less $\bar{\theta}$ variance at the top of the CBL. A sharper maximum in $\overline{\theta^{\prime 2}}$ can be observed in CONTROL and UNI if compared to TOP. Analyzing the $\overline{\theta^{\prime 2}}$ budget enables us to study the responsible physical mechanism that leads to the decrease in the potential temperature variance. Following Stull (1988), Mauritsen et al. (2007), Zilitinkevich et al. (2007), and Zilitinkevich etal. (2008), the potential temperature variance budget (explicitly considering the radiation term) reads

$$
\frac{1}{2} \frac{\overline{D \theta^{\prime} \theta^{\prime}}}{D t}=-\overline{w^{\prime} \theta^{\prime}}\left(\frac{\partial \bar{\theta}}{\partial z}\right)-\frac{1}{2} \frac{\partial \overline{w^{\prime} \theta^{\prime} \theta^{\prime}}}{\partial z}-\frac{1}{\rho c_{p}} \overline{\theta^{\prime}} \frac{\partial F^{\prime}}{\partial z}-\epsilon_{d},
$$




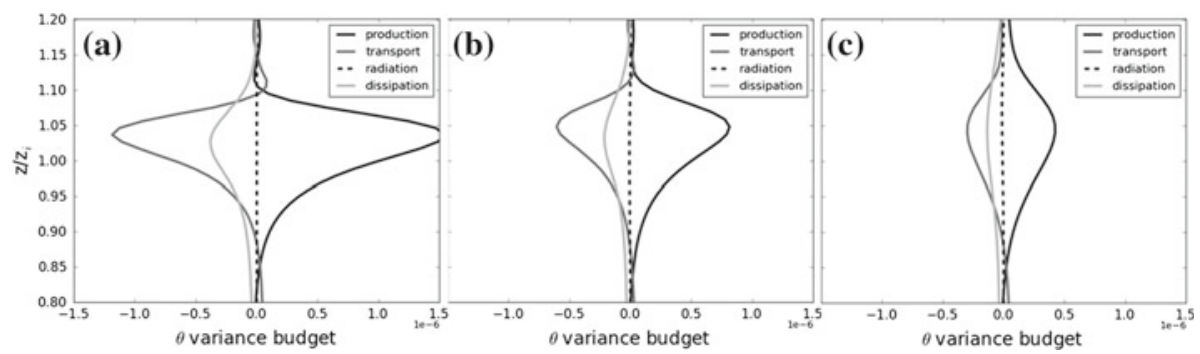

Fig. 8 Budget of the last-hour horizontally-averaged potential temperature variance normalized by $w_{*} \theta_{*} / z_{i}$ for a CONTROL, $\mathbf{b}$ UNI and $\mathbf{c}$ TOP. To focus on the EZ characteristics, the budgets are shown from $(0.8-1.2)$ $z / z_{i}$

where the term in the left-hand side is the tendency of the potential temperature variance. The first term on the right-hand side is the production of potential temperature variance, the second indicates the variance vertical transport, the third is the production/destruction of variance due to radiation absorption (also called $\epsilon_{R}$ ) and the fourth is the dissipation of potential temperature variance. Figure 8 shows the vertical profiles of the $\bar{\theta}$ variance budgets in all cases.

The production term $\left[\overline{w^{\prime} \theta^{\prime}}\left(\frac{\partial \bar{\theta}}{\partial z}\right)\right]$ is reduced for both UNI and TOP by different magnitudes due to the diminution in the $\left(\frac{\partial \bar{\theta}}{\partial z}\right)$, (see Fig. 5b), since the entrainment rates of UNI and TOP are identical. The transport term indicates that all the $\bar{\theta}$ variance is constrained within the EZ since it is transported to the same place as where it is produced and dissipated. The $\epsilon_{R}$ term is not significant for any of the simulations remaining around $1-10 \%$ of $\epsilon_{d}$ for all the cases (Stull 1988).

The vertical profiles of the potential temperature anomaly (Fig. 5a), Brunt-Väis $\ddot{a} 1 \ddot{a}$ frequency (Fig. 5b), together with TKE decreasing and conversion to horizontal movements for TOP (Fig. 6b) signify that the upper CBL becomes stably stratified at lower heights. In short, we find that in the presence of aerosols, the initially sharper potential temperature gradient at the entrainment zone becomes less strong (Fig. 5b), but wider and more stratified. This further confirms the decrease in $\bar{\theta}$ variance (Fig. 7) caused by the diminished $\bar{\theta}$ vertical gradient (Figs. 5b and 8) at the top of the CBL.

\section{Conclusions}

We studied the impact of the aerosol heat absorption on the convective atmospheric boundarylayer (CBL) dynamics. Idealised CBL flows characterized by aerosols distributed (i) uniformly in the whole CBL or (ii) only within the CBL's upper $200 \mathrm{~m}$ were compared with a clear, i.e. no aerosols, CBL case. All the experiments were simulated using the large-eddy simulation (LES) technique. For all the cases the CBL was designed in such a manner that the entrainment velocity was compensated by the subsidence motions yielding to a constant CBL depth after sufficiently lengthy integration.

We first investigated how the absorbing aerosols perturb the CBL depth-equilibrium by shadowing the surface. We found reduced CBL depth and potential temperature inversion jump when aerosols were present, although these were more intense when the aerosols were concentrated only at the top of the CBL. To further support the analysis of the LES results, 
we used mixed-layer theory to derive steady-state analytical solutions for boundary-layer depth and potential temperature jump at the inversion layer. In spite of their simplicity, the mixed-layer results agreed well with the LES data for all the experiments.

The reduction in the surface heat flux enabled us to partially explain the shallower CBL, but not the different equilibrium depths. Our explanation is the following: besides the reduced surface heat flux, the LES results also showed changes in the entrainment zone (EZ) stratification profile. On the one hand, the potential temperature inversion jump becomes weaker as a result of the heat absorption, while on the other, we observed the EZ depth increasing 18 and $91 \%$ when aerosols were uniform or concentrated at the top of the CBL. The impact of aerosols on modifying the stratification of the upper mixed layer was also corroborated by the larger values of the potential temperature anomaly and the Brunt-Väis $\ddot{a} l \ddot{a}$ frequency at lower levels. The combination of these mechanisms explained the different characteristics of the CBL for different vertical distribution of aerosols.

We further studied the aerosol heat absorption effects on the vertical structure of the CBL by quantifying the heat budget at the EZ. Even though the minimum entrainment flux fell by $12.5 \%$ when aerosols were present (controlled by the surface forcing), the heat budget analysis confirmed the more significant deepening of the EZ when the aerosols were found only at the top of the CBL.

To complete our analysis, we studied the aerosol heat absorption impact on the velocity and potential temperature variance profiles. The horizontal velocity variance profiles showed that aerosol absorption of heat reduces the horizontal velocity peak at the top of the CBL because less momentum is transferred from the updrafts when the inversion layer was weaker. When aerosols are located solely at the top of the CBL, the reduced vertical motions throughout the CBL corroborated the steep decrease in turbulent kinetic energy. This was explained by the broadening of the stable stratified region already below the EZ, weakening the turbulent eddies at lower levels. The ratio $\frac{\overline{w^{\prime 2}}}{\overline{u^{\prime 2}}+\overline{v^{\prime 2}}}$ on average diminished when aerosols were at the top of the CBL indicating the earlier conversion of vertical motion into horizontal components.

The peak in the variance of the potential temperature in the EZ was reduced but an earlier onset was observed. Its budget further explained how the reduced potential temperature gradient observed when aerosols are present was the responsible physical mechanism for diminishing the $\bar{\theta}$ variance.

To conclude, this study evidenced the importance of high resolution models to properly simulate the effects of aerosol absorption of radiation on the dynamics of the CBL. Moreover, we have demonstrated that in addition to the properties of the aerosols, the vertical distribution is an important characteristic to properly describe the CBL height evolution and the dynamics of the EZ. In a future study we plan to include explicitly the effects of the SW diurnal cycle and an on-line coupling between the aerosol layer and the SW radiation field.

Acknowledgements The authors gratefully thank Sasha Madronich of NCAR for his very useful discussion of the radiative transfer results. The research was supported by the NWO grant on computer time (SH-060-12).

Open Access This article is distributed under the terms of the Creative Commons Attribution License which permits any use, distribution, and reproduction in any medium, provided the original author(s) and the source are credited.

\section{References}

Ackerman TP (1977) A model of the effect of aerosols on urban climate with particular applications to the Los Angeles basin. J Atmos Sci 34:531-547 
Angevine WM, Grimsdell AW, Mckeen SA (1998) Entrainment results from the FLATLAND boundary layer experiments. J Geophys Res 103(98):13689-13701

Betts AK (1974) Reply to comment on the paper "non-precipitating Cumulus convection and its parameterization". Q J R Meteorol Soc 100:469-471

Bierwirth E, Wendisch M, Jäkel E, Ehrlich A, Schmidt KS, Stark H, Pilewskie P, Esselborn M, Gobbi GP, Ferrare R, Müller T, Clarke A (2010) A new method to retrieve the aerosol layer absorption coefficient from airborne flux density and actinic radiation measurements. J Geophys Res, 115(D14)

Bretherton C, Macvean M, Bechtold P, Chlond A, Cotton W, Cuxart J, Cuijpers H, Khairoutdinov M, Kosovic B, Lewellen D, Moeng C-H, Sibiesma P, Stevens B, Stevend D, Sykes I, Wyant M (1999) An intercomparison of radiatively driven entrainment and turbulence in a smoke cloud, as simulated by different numerical models. Q J R Meteorol Soc 125(554):391-423

Charlson R, Schwartz S, Hales J, Cess R, Coakley J, Hansen J, Hoffmann D (1992) Climate forcing by anthropogenic aerosols. Science 255:423-430

Conant WC (2002) Black carbon radiative heating effects on cloud microphysics and implications for the aerosol indirect effect 1. extended Köhler theory. J Geophys Res, 107(D21)

Cuijpers JWM, Holtslag AAM (1998) Impact of skewness and nonlocal effects on scalar and buoyancy fluxes in convective boundary layers. J Atmos Sci 55(2):151-162

De Roode SR, Duynkerke PG, Boot W, Van der Hage JCH (2001) Surface and tethered-balloon observations of actinic flux: effects of arctic stratus, surface albedo, and solar zenith angle. J Geophys Res 106(D21):2749727507

Duynkerke PG, Zhang H, Jonker P (1995) Microphysical and turbulent structure of nocturnal Stratocumulus as observed during ASTEX. J Atmos Sci 52:2763-2777

Fernando H (1991) Turbulent mixing in stratified fluids. Annu Rev Fluid Mech 23:455-493

Forster P, Ramaswamy V, Artaxo P, Berntsen T, Betts R, Fahey D, Haywood J, Lean J, Lowe D, Myhre G, Nganga J, Prinn R, Raga G, Schulz M, Dorland RV (2007) Changes in atmospheric constituents and in radiative forcing. In: Climate Change, (2007) The Physical Science Basis. Contribution of Working Group I to the Fourth Assessment Report of the Intergovernmental Panel on Climate Change, Cambridge University Press, Cambridge

Gao RS, Hall SR, Swartz WH, Schwarz JP, Spackman JR, Watts La, Fahey DW, Aikin KC, Shetter RE, Bui TP (2008) Calculations of solar shortwave heating rates due to black carbon and ozone absorption using in situ measurements. J Geophys Res, 113(D14)

Garratt JR (1992) The atmospheric boundary layer. Cambridge University Press, Cambridge, UK

Heus T, van Heerwaarden CC, Jonker HJJ, Siebesma AP, Axelsen S, van den Dries K, Geoffroy O, Moene A, Pino D, de Roode SR (2010) Formulation of the dutch atmospheric large-eddy simulation (DALES) and overview of its applications. Geosci Model Dev 3:415-444

Hewitt CN, Jackson A (2009) Atmospheric science for environmental scientists. Wiley-Blackwell, New York

Jacobson MZ (1998) Studying the effects of aerosols on vertical photolysis rate coefficient and temperature profiles over an urban airshed. J Geophys Res, 103(D9): 10593-10604

Jochum A, Rodriguez Camino E, De Bruin H, Holtslag AAM (2004) Performance of HIRLAM in a semiarid heteregeneous region: Evaluation of the land surface and boundary layer description using EFEDA observations. Mon Weather Rev 132:2745-2760

Johnson BT, Heese B, McFarlane Sa, Chazette P, Jones a, Bellouin N (2008) Vertical distribution and radiative effects of mineral dust and biomass burning aerosol over West Africa during DABEX. J Geophys Res, 113(D00C12)

Kaufman Y, Tanr D, Boucher O (2002) A satellite view of aerosols in the climate system. Nature 419:215-223

Landgraf J, Crutzen PJ (1998) An efficient method for online calculations of photolysis and heating rates. J Atmos Sci 55(5):863-878

Li Z, Xia X, Cribb M, Mi W, Holben B, Wang P, Chen H, Tsay SC, Eck TF, Zhao F, Dutton EG, Dickerson RE (2007) Aerosol optical properties and their radiative effects in northern China. J Geophys Res, 112(D22)

Lilly DK (1968) Models of cloud-topped mixed-layer under a strong inversion. Q J R Meteorol Soc 94:292-309

Liou K (2002) An introduction to atmospheric radiation. Academic Press, New York, p 5831

Liu H, Pinker RT, Holben BN (2005) A global view of aerosols from merged transport models, satellite, and ground observations. J Geophys Res 110(D10S15)

Madronich S (1987) Photodissociation in the atmosphere 1. Actinic flux and the effects of ground reflections and clouds. J Geophys Res 92:9740-9752

Malavelle F, Pont V, Mallet M, Solmon F, Johnson B, Leon JF, Liousse C (2011) Simulation of aerosol radiative effects over west africa during DABEX and AMMA SOP-0. J Geophys Res 116(D8)

Masson V, Gomes L, Pigeon G, Liousse C, Pont V, Lagouarde J-P, Voogt J, Salmond J, Oke TR, Hidalgo J, Legain D, Garrouste O, Lac C, Connan O, Briottet X, Lachérade S, Tulet P (2008) The canopy and 
aerosol particles interactions in toulouse urban layer (CAPITOUL) experiment. Meteorol Atmos Phys 102(3-4):135-157

Mauritsen T, Svensson G, Zilitinkevich SS, Esau I, Enger L, Grisogono B (2007) A total turbulent energy closure model for neutrally and stably stratified atmospheric boundary layers. J Atmos Sci 64(11):41134126

Moeng CH (1984) A large-eddy-simulation model for the study of planetary boundary-layer turbulence. J Atmos Sci 41:2052-2062

Moeng C-H, Wyngaard JC (1988) Spectral analysis of large-eddy simulations of the convective boundary layer. J Atmos Sci 45:3573-3587

Nieuwstadt FTM, Brost RA (1986) The decay of convective turbulence. J Atmos Sci 43:532-545

Pino D, Vilà-Guerau de Arellano J (2008) Effects of shear in the convective boundary layer: analysis of the turbulent kinetic energy budget. Acta Geophys 56(1):167-193

Quijano AL, Sokolik IN, Toon OB (2000) Radiative heating rates and direct radiative forcing by mineral dust in cloudy atmospheric conditions. J Geophys Res 105(D10):12207-12219

Raga G, Castro T, Baumgardner D (2001) The impact of megacity pollution on local climate and implications for the regional environment: Mexico city. Atmos Environ 35(10):1805-1811

Satheesh S, Ramanathan V (2000) Large differences in tropical aerosol forcing at the top of the atmosphere and Earth's surface. Nature 405(6782):60-63

Stockwell W, Goliff W (2004) Measurement of actinic flux and calculation of photolysis rate parameters for the central California Ozone study. Atmos Environ 38:5169-5177

Stull RB (1988) An introduction to boundary layer meteorology. Kluwer Academic Publishers, Dordecht, 680 pp

Sullivan P, McWilliams J, Moeng C-H (1994) A subgrid scale model for large-eddy simulation of planetary boundary-layer flows. Boundary-Layer Meteorol 71:276-276

Sullivan PP, Moeng C-H, Stevens B, Lenschow DH, Mayor SD (1998) Structure of the entrainment zone capping the convective atmospheric boundary layer. J Atmos Sci 55:3042-3064

Tennekes H (1973) A model for the dynamics of the inversion above a convective boundary layer. J Atmos Sci 30:558-567

Tripathi SN (2005) Aerosol black Carbon radiative forcing at an industrial city in northern India. Geophys Res Lett 32(8):L08802

Van Zanten MC, Duynkerke PG, Cuijpers JWM (1999) Entrainment parameterization in convective boundary layers. J Atmos Sci 56(6):813-828

Vilà-Guerau de Arellano J, Cuijpers JWM (2000) The chemistry of a dry cloud: the effects of radiation and turbulence. J Atmos Sci 57:1573-1584

Wong DC, Pleim J, Mathur R, Binkowski F, Otte T, Gilliam R, Pouliot G, Xiu a, Young JO, Kang D (2012) WRF-CMAQ two-way coupled system with aerosol feedback: software development and preliminary results. Geoscientific Model Dev 5(2):299-312

Yu H, Liu SC, Dickinson RE (2002) Radiative effects of aerosols on the evolution of the atmospheric boundary layer. J Geophys Res 107(D12)

Zdunkowski W, Welch R, Paegle J (1976) One-dimensional numerical simulation of the effects of air pollution on the planetary boundary layer. J Atmos Sci 33:2399-2414

Zilitinkevich S, Elperin T, Kleeorin N, Rogachevskii I (2007) Energy-and flux-budget (EFB) turbulence closure model for stably stratified flows. Part I: steady-state, homogeneous regimes. Boundary-Layer Meteorol 125:167-191

Zilitinkevich SS, Elperin T, Kleeorin N, Rogachevskii I, Esau I, Mauritsen T, Miles MW (2008) Turbulence energetics in stably stratified geophysical flows: strong and weak mixing regimes. Q J R Meteorol Soc 134:793-799 